\title{
Positive feedback praising good performance does not alter the learning of an intrinsically motivating task in 10-year-old children
}

\author{
Ricardo Drews ${ }^{1,2}$, Go Tani ${ }^{3}$, Priscila Cardozo ${ }^{2}$, Suzete Chiviacowsky ${ }^{2}$ \\ 1. Universidade Federal de Uberlândia, Brasil; \\ 2. Universidade Federal de Pelotas, Brasil \\ 3. Universidade de São Paulo, Brasil
}

* Correspondence: (Suzete Chiviacowsky) suzete@ufpel.edu.br

Received: 05/05/2020; Accepted: 15/11/2020 Published: 31/12/2020

\begin{abstract}
Several studies have provided evidence for the importance of motivation in motor learning. The present study investigates whether providing positive feedback as statements praising good performance would benefit children's motor learning when compared to a nopraise condition. Thirty 10-year-old children divided into two groups-positive feedback (PF) and control-learned to ride a pedalo over a seven-meter distance in the shortest time possible. Participants performed 20 practice trials and received feedback on their movement time following each trial. However, only the PF group received feedback acknowledging good performance after each trial block. After 24 hours, both groups performed learning tests without any feedback. Questionnaires (Intrinsic Motivation Inventory) were applied to measure participants' motivational levels. The results show substantial improvements in performance during practice and high levels of intrinsic motivation, sustained across days, in both groups. Differences between groups in motivation, performance, and learning were not found. These results demonstrate that riding a pedalo in the shortest time possible constitutes an intrinsically motivating task in children, whose learning is not altered by the provision of positive feedback statements acknowledging good performance, possibly by a motivational ceiling effect. The findings indicate that task-inherent motivational characteristics can moderate positive feedback learning effects in children. Future studies could measure other motivational constructs, such as learner's persistence in practicing the task, or could include post-failure measures that may reveal differences in children's capacity to cope with errors. Differences between groups would demonstrate potential benefits of providing positive feedback praising performance in children that were not captured in the present experiment, even on the learning of inherently motivating tasks.
\end{abstract}

Keywords: Motor learning; intrinsic motivation; enjoyment; competence; expectancies; infancy; balance.

\section{Introduction}

The motor learning phenomenon is a set of processes associated with practice or experience, not directly observable, leading

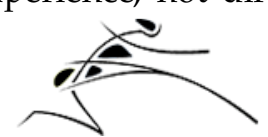

(C) 2020 Drews et al., licensee EURJHM. This is an Open Access article distributed under the terms of the Creative Commons Attribution License ((http://creativecommons.org/licenses/by/4.0/) which permits unrestricted use, distribution, and reproduction in any medium, provided the original work is properly cited. to relatively permanent changes in the capability for skilled movement (Schmidt, Lee, Winstein, Wulf, \& Zelaznik, 2019). Over the last two decades, several studies have demonstrated the important role of 
motivation in motor learning (see Chiviacowsky, 2020; Jaitner \& Mess, 2019; Lewthwaite \& Wulf, 2012; Sanli, Patterson, Bray, \& Lee, 2013). Self-Determination Theory (Ryan \& Deci, 2000; 2020), and the recent OPTIMAL theory of motor learning (Wulf \& Lewthwaite, 2016) have provided fruitful frameworks for such research. Intrinsic motivation is based on people's inherent interest and enjoyment of activities done "for their sake", not dependent on external pressures or incentives, and those that support individuals' basic psychological needs (Deci \& Ryan, 2000). Motivational effects include the generation of dopaminergic responses, thought to strengthen memory and learning (Wise, 2004), and develop more efficient goal-action coupling, thus benefiting motor learning (Wulf \& Lewthwaite, 2016).

The effects of motivation on motor learning have been investigated in several contexts, tasks, and populations-mainly in young adults. Most studies have observed the motivational properties of learning factors related to the innate human psychological need for autonomy (e.g., Chiviacowsky, 2014; Iwatsuki, Shih, Abdollahipour, \& Wulf, 2019), competence (e.g., Abbas \& North, 2018; Chiviacowsky \& Harter, 2015; Ziv, Lidor, \& Lavie, 2019), and relatedness (Chiviacowsky, Harter, Del Vecchio, \& Abdollahipour, 2019; Gonzalez \& Chiviacowsky, 2018).

The effects of motivation in children's motor learning have also been tested. Studies have demonstrated that providing autonomy support through choices over feedback (Chiviacowsky, Wulf, Medeiros, Kaefer, \& Tani 2008; Ste-Marie, Vertes, Law, \& Rymal, 2013), model observation (Lemos, Wulf, Lewthwaite, \& Chiviacowsky, 2017), or even through task-irrelevant choices as ball color (Abdollahipour, Nieto, Psotta, \& Wulf, 2017), positively impacts their learning. Other studies have observed positive impacts on children's learning by supporting their competence need through different motivational factors, as feedback after more successful trials (Saemi, Wulf, Varzaneh, \& Zarghami, 2011), social-comparative feedback (Ávila, Chiviacowsky, Wulf, \& Lewthwaite, 2012; Gonçalves, Cardozo, Valentini, \& Chiviacowsky, 2018), adapted self-as-a-model (Clark \& Ste-Marie, 2007), conceptions of ability (Chiviacowsky \& Drews, 2014; Drews, Chiviacowsky, \& Wulf, 2013; Harter, Cardozo, \& Chiviacowsky, 2018), and also through optical illusions (Bahmani, Wulf, Ghadiri, Karimi, \& Lewthwaite, 2017).

Research investigating the effects on children's motor learning when providing positive feedback statements acknowledging good performance, not relying on socialcomparison (e.g., Ávila et al., 2012; Gonçalves et al., 2018) is, however, still scarce. In two experiments, Chiviacowsky and Drews (2014) observed the effects of different conceptions of ability induced by feedback praising performance (e.g., "The last kicks were great", "These last throws were very good"), versus more generic feedback praising the person (e.g., "You are a great soccer player", "You have a talent for throwing"). Children receiving feedback praising their performance showed benefits on motor performance and learning in comparison to children provided with feedback praising the person. To date, yet, no studies have investigated the effects of such feedback praising performance against a nopraise condition on children's motor learning. Praise can benefit motivation when it is perceived as sincere, conveys attainable standards and expectations, enhances competence without an overreliance on social comparisons, is provided in an autonomous way, and highlights the performance or process, not the person (Henderlong \& Lepper, 2002; Kamins \& Dweck, 1999).

The objective of the present study was to examine whether providing positive feedback as statements praising good performance would increase motivation and affect the learning of a motor task in children. We asked two groups of participantspositive feedback (PF) and control-to practice riding a pedalo over a distance of seven meters in the shortest time possible. Considering the dearth of studies on the 
effects of positive feedback in children, and the important motivational role of feedback in motor learning (Chiviacowsky, 2020), we considered it important to conduct such research. We hypothesized higher levels of intrinsic motivation and enhanced learning for the PF group relative to the control group.

\section{Materials and Methods}

\section{Subjects}

Thirty 10-year-old children (16 females, Mage $=10.43$ years) without previous experience with the task participated in this study. An invitation was advertised in a public school in southern Brazil in order to recruit participants, and the following inclusion criteria were employed: chronological age between 10 and 11 years, and no prior experience with the task. Children willing to participate in the experiment provided their assent, and informed consent was obtained from participants' schools and their parents or guardians. The Ethics Committee of the University approved the study.

\section{Methodology}

The task, similar to that used by Flôres, Schild, and Chiviacowsky (2015), required participants to ride a pedalo along a distance of seven meters in the shortest time possible, demarcated by starting and finishing lines. The pedalo is a dispositive that moves when the top platform is pushed back and forth (similar to pedals of a bicycle). Its use involves global body coordination and, above all, maintaining balance. All trials started with the children's right foot on the upper platform and the data collection began as soon as the wheels of the pedalo touched the starting line. A timer was used to measure the movement time (MT): the time between the start and finish lines.

\section{Experimental design}

The experiment consisted of three phases: practice, retention, and transfer. Participants were randomly assigned to a positive feedback group (PF) or a control group, and the groups were matched according to sex and age. Participants were naïve as to the objective of the study. Before starting practice, all participants were informed about the goal of the task, the total number of trials, the study phases, and the questionnaires to be completed, and observed a demonstration of how to perform the task.

All participants completed 20 practice trials and received feedback consisting of the time it took them to complete the distance, in seconds, after each trial. Participants in the $\mathrm{PF}$ group received additional positive feedback statements praising performance after each block of five trials (see Table 1). One day later, the participants performed retention and transfer tests, with five trials each, without any feedback. Retention trials were identical to the practice trials, whereas in the transfer test (measuring adaptation to a novel situation) the participants performed the task holding a pole with both hands on the horizontal axis. The participants completed the Intrinsic Motivation Inventory (IMI) (McAuley, Duncan, \& Tammen, 1989; McAuley, Wraith, \& Duncan, 1991; Whitehead \& Corbin, 1991) at the end of practice and before retention the next day. For each domain evaluated (competence, effort, enjoyment, and nervousness, respectively measuring the extent to which the participants felt effective/efficacious, put forth effort and invested capacities, felt joy/interest, and experienced nervousness when performing the task), there were three questions with four possible answers, ranging from "did not enjoy" to "enjoyed very much" and with appropriate smiling or frowning faces accompanying each response (e.g., see Ávila et al., 2012). The responses to each statement were assigned 1, 4, 7 or 10 points, respectively, for analysis purposes.

Table 1. Positive feedback statements provided to the PF group during the practice phase

\begin{tabular}{|c|c|}
\hline Trials & Positive Feedbacks \\
\hline $5^{\mathrm{a}}$ & $\begin{array}{l}\text { "You did a great job on these first } \\
\text { trials" }\end{array}$ \\
\hline $10^{\mathrm{a}}$ & $\begin{array}{l}\text { "Very good! You are increasing your } \\
\text { speed fast" }\end{array}$ \\
\hline $15^{\mathrm{a}}$ & $\begin{array}{l}\text { "It's great! You are riding the pedalo } \\
\text { very well" }\end{array}$ \\
\hline $20^{\mathrm{a}}$ & "You did an excellent job!" \\
\hline
\end{tabular}




\section{Statistical Analysis}

Movement time acted as a dependent variable. The practice data was analyzed in a 2 (group) $X$ 20 (trials) ANOVA with repeated measures in the last factor. Retention and transfer tests data were analyzed separately in 2 (group) X 5 (trials) separate ANOVAs, with repeated measures in the last factor. Separated one-way ANOVAs were used for the questionnaire responses. The alpha was set at 0.05 for all analyses. SPSS software version 22 was used to analyze the data.

\section{Results}

\section{Movement times (MT)}

Practice. Both groups decreased their MT from the first to the last block of trials during practice (see Figure 1). The main effect of trial was significant, $F(19$, $532)=25.567, p<.001, \eta p^{2}=.477$, while the main effect of group, $F(1$, $28)=.925, p=.344, \eta p^{2}=.032$, and the interaction of group and trial were not significant, $F(19,532)=$ $.739, p=.622, \eta p^{2}=.026$.

Retention. On the retention test, the main effect of trial, $F(4,112)=1.794$, $p=.135, \eta p^{2}=.060$, group, $F(1,28)=.602, p=$ $.444, \eta p^{2}=.021$, and the interaction between group and trial, $F(4,112)=.087, p=.986, \eta p^{2}$ $=.003$, were not significant.

Transfer. On the transfer test, the main effect of trial was significant, $F(4,112)=$ 4.332, $p=.003, \eta p^{2}=.134$. The effects of group, $F(1,28)=.134, p=.717, \eta p^{2}=.005$, and interaction of group and trial, $F(4,112)=.087$, $p=.986, \eta p^{2}=.003$, were not significant.

\section{Questionnaire}

Post-practice. Following the practice phase, the groups did not differ in terms of perceived competence, $F(1,28)=.104, p=$ $.302, \eta p^{2}=.038$. Similar results were found in terms of effort, $F(1,28)=1.200, p=.556, \eta p^{2}$ $=.013$, enjoyment, $F(1,28)=.000, p=1.000, \eta p^{2}$
$=.000$, and nervousness, $F(1,28)=.136, p$ $=.715, \eta p^{2}=.005$.

Pre-retention. The groups did not differ also in terms of perceived competence before the retention test, $F(1,28)=.188, p$ $=668, \eta p^{2}=0.007$. In a similar way, the main effect of group regarding effort, $F(1,28)$ $=.008, p=.931, \eta p^{2}=.000$, enjoyment, $F(1,28)$ $=.030, p=.863, \eta p^{2}=.001$, and nervousness, $F$ $(1,28)=.280, p=.631, \eta p^{2}=.010$, were not significant. The questionnaire results are shown in Figure 2.

\section{Discussion}

Several studies have shown that motivation plays an important role in motor learning across different tasks and populations, including children (Ávila et al., 
2012; Gonçalves et al., 2018; Saemi et al., 2011). The aim of the present study was to examine whether providing feedback as statements praising good performance (e.g., Chiviacowsky \& Drews, 2014) would benefit children learning to ride a pedalo. The results revealed a robust pattern of improvement in participants' task performance during practice; high levels of intrinsic motivation were reported in both days. Significant differences in motivation, performance and learning were not found between groups, indicating that feedback praising performance did not add benefits to the learning of the pedalo task in 10-year-old children.

The presented results can be explained as follows. The high levels of enjoyment (scores close to maximum) reported on both experimental days by both groups revealed that riding the pedalo constituted a truly intrinsically motivating task to the participants. The interest/enjoyment subscale of the IMI is considered a direct self-report measure of intrinsic motivation per se (McAuley et al., 1989). Great levels of enjoyment in a task can preserve intrinsic motivation, even in situations when positive feedback is absent (e.g., Katz, Assor, Kanat-Maymon, \& BerebyMeyer, 2006). Therefore, the resulting high enjoyment level reported by the participants may have benefited learning, limiting increases in motivation and consequent learning as a function of the additional positive feedback.

The raised levels of enjoyment caused by the pedalo task may have distinct but related explanations. Intrinsic motivation is settled on people's natural interest in activities that provide novelty and optimal levels of stimulation or challenges, while supporting basic psychological needs (Deci \& Ryan, 2010). The novelty of the situation (first contact of the children with a pedalo) and the optimal challenging characteristics of the task may have created an inherently motivating task that increased children's intrinsic motivation and learning to a point difficult to overcome by using the positive feedback statements. The positive feedback effects could have been moderated by a motivational ceiling effect.

Novelty is a candidate need in the basic psychological needs theory (Vansteenkiste, Ryan, \& Soenens, 2020). It involves an inherent desire to experience new contexts and situations, to feel new sensations, to seek out and engage in new activities, positively impacting intrinsic motivation (González-Cutre, Romero-Elias, Jiménez-Loaisa, Beltrán- Carrillo, \& Hagger, 2020; González-Cutre, Sicilia, Sierra, Ferriz, \& Hagger, 2016; Vansteenkiste et al., 2020). Curiosity, exploration, and play-inherent propensities of interested task engagement and mastery of intrinsically motivated behaviors-are undeniably responsible for part of human learning across the life span (Ryan \& Deci, 2020).

Riding the pedalo in the shortest time possible, associated with an experience of success, may have generated a level of challenge that also positively affected children's motivation. In fact, children's performance across the practice trials demonstrates a high and consistent pattern of improvement, allowing abundant positive accomplishment experiences. The benefits of "optimal" challenges upon motivation and learning have already been observed in experiments using harder or easier criteria of success (Chiviacowsky, Wulf, \& Lewthwaite, 2012; Chiviacowsky \& Harter, 2015; Palmer, Chiviacowsky, \& Wulf, 2016; Trempe, Sabourin, \& Proteau, 2012). In these studies, the participants' (subjective) perceptions of success were modulated by instructions informing what constitutes good performance. The results have shown that relatively easier criterion of good performance (allowing challenge with experience of success) enhance perceptions of competence and learning relative to harder criterion, where the learner's experience of success is rare during practice.

Participants of both groups in the present experiment also received feedback about the time (in seconds) it took them to complete each ride following every trial. Different from tasks that involve throwing or kicking implements to targets (e.g., Ávila et 
al., 2012; Chiviacowsky \& Drews, 2014; Gonçalves et al., 2018), riding the pedalo as quickly as possible become a task without spatial or temporal "errors" to correct. Instead, any improvement in speed-no matter how small-can be considered a successful trial. Positive feedback informing participants that performance is continually improving over time, so-called temporalcomparative feedback, was observed to increase perceptions of competence and motor learning in adults (e.g., Chiviacowsky \& Drews, 2016; Chiviacowsky, Harter, Gonçalves, \& Cardozo, 2019; Lessa, Tani, \& Chiviacowsky, 2018). Thus, information that continually notified participants of task success may have acted in parallel with the praises, attenuating praise motivational effects or even making it redundant.

In conclusion, the present findings demonstrate that the provision of additive feedback that praises good performance does not alter the learning of an inherently enjoyable motor task in children. The intrinsically motivating character of the task maintained learner's motivation to a point where no additional benefits could be observed upon motivation and learning (e.g., ceiling effect), moderating or nullifying the effects of the additional positive feedback. The present study was limited to investigating whether providing positive feedback statements praising good performance would benefit children's intrinsic motivation and learning of riding a pedalo along a distance of seven meters, in the shortest time possible, relative to a nopraise condition. Follow-up studies could make use of other motivational constructs to better understand the processes underlying feedback effects; for example, evaluating participants' persistence or willingness to continue practicing the task. The inclusion of post-failure measures (e.g., Chiviacowsky \& Drews, 2014; Cimpian, Arce, Markman, \& Dweck, 2007) could also reveal potential differences in the participants' capacity to cope with errors during the learning process. Differences between groups, if present, could reveal the benefits of providing positive feedback as statements praising good performance that were not captured in the present experiment, even on the learning of highly intrinsically motivating tasks.

The effects of performance-praising feedback could also be tested using other tasks, or without concurrent provision of other forms of feedback. As observed in the literature, the effects on motor learning of positive feedback in the form of praise can vary depending on the wording and meaning they convey, for example, non-generic feedback praising performance versus more generic feedback praising the person, while inducing different conceptions of ability (e.g., Chiviacowsky \& Drews, 2014). Perhaps the effects may also vary depending on the learner's characteristics, the peculiarities of the tasks, or the context by which they are delivered. Future studies answering these questions could advance our knowledge of the effects and underlying mechanisms of feedback on motivation, motor performance, and learning. As practical applications, we suggest that professionals involved in teaching-learning contexts of motor skills make use of diverse forms of increasing individuals' motivation during practice, including not only the use of positive feedback, but also intrinsically motivating tasks, to facilitate learning.

Funding: Non-declared

Acknowledgments: Non-declared

Conflicts of Interest: The authors declare no conflict of interest.

\section{References}

Abbas, Z. A., \& North, J. S. (2018). Good-vs. poortrial feedback in motor learning: The role of self-efficacy and intrinsic motivation across levels of task difficulty. Learning and Instruction, 55, 105-112. https://doi.org/10.1016/j.learninstruc.2017 .09 .009

Abdollahipour, R., Nieto, M. P., Psotta, R., \& Wulf, G. (2017). External focus of attention and autonomy support have additive benefits for motor performance in children. Psychology of Sport and Exercise, 32, 17-24. http://dx.doi.org/10.1016/j.psychsport.201 7.05.004

Ávila, L. T., Chiviacowsky, S., Wulf, G., \& Lewthwaite, R. (2012). Positive social- 
comparative feedback enhances motor learning in children. Psychology of Sport and Exercise, 13, 849-853. https://doi.org/10.1016/j.psychsport.2012. 07.001

Bahmani, M., Wulf, G., Ghadiri, F., Karimi, S., \& Lewthwaite, R. (2017). Enhancing performance expectancies through visual illusions facilitates motor learning in children. Human Movement Science, 55, 1-7. http://dx.doi.org/10.1016/j.humov.2017.07 .001

Chiviacowsky, S. (2014). Self-controlled practice: Autonomy protects perceptions of competence and enhances motor learning. Psychology of Sport and Exercise, 15, 505510.

https://doi.org/10.1016/j.psychsport.2014. 05.003

Chiviacowsky, S. (2020). The motivational role of feedback in motor learning: evidence, interpretations, and implications. In: $\mathrm{M}$. Bertollo, E. Filho, \& P. C. Terry (Eds.). Advancements in Mental Skills Training. (London: Routledge), 44-56. https://doi.org/10.4324/9780429025112

Chiviacowsky, S., \& Drews, R. (2014). Effects of generic versus non-generic feedback on motor learning in children. PloS One, 9(2), e88989.

http://dx.doi.org/10.1371/journal.pone.00 88989.

Chiviacowsky, S., \& Drews, R. (2016). Temporalcomparative feedback affects motor learning. Journal of Motor Learning and Development, 4, 208-218. https://doi.org/10.1123/jmld.2015-0034

Chiviacowsky, S., \& Harter, N. M. (2015). Perceptions of competence and motor learning: performance criterion resulting in low success experience degrades learning. Brazilian Journal of Motor Behavior, 9. https://doi.org/10.20338/bjmb.v9i1.82

Chiviacowsky, S., Harter, N., Del Vecchio, F., \& Abdollahipour, R. (2019). Relatedness affects eye blink rate and movement form learning. Journal of Physical Education and Sport, 19, 859-866. http://dx.doi.org/10.7752/jpes.2019.s3124

Chiviacowsky, S., Harter, N. M., Gonçalves, G. S., \& Cardozo, P. L. (2018). Temporalcomparative feedback facilitates golf putting. Frontiers in Psychology, 9, 2691. https://doi.org/10.3389/fpsyg.2018.02691

Chiviacowsky, S., Wulf, G., de Medeiros, F. L., Kaefer, A., \& Tani, G. (2008). Learning benefits of self-controlled knowledge of results in 10-year-old children. Research Quarterly for Exercise and Sport, 79, 405-410. https://doi.org/10.1080/02701367.2008.105 99505

Cimpian, A., Arce, H. M. C., Markman, E. M., \& Dweck, C. S. (2007). Subtle linguistic cues affect children's motivation. Psychological Science, 18, 314-316. doi:10.1111/j.14679280.2007.01896.x

Clark, S. E., \& Ste-Marie, D. M. (2007). The impact of self-as-a-model interventions on children's self-regulation of learning and swimming performance. Journal of Sports Sciences, 25(5), 577-586. https://doi.org/10.1080/0264041060094709 0

Deci, E. L., \& Ryan, R. M. (2000). The" what" and" why" of goal pursuits: Human needs and the self-determination of behavior. Psychological Inquiry, 11, 227-268. https://doi.org/10.1207/S15327965PLI1104 -01

Deci, E. L., \& Ryan, R. M. (2010) Intrinsic Motivation, The Corsini Encyclopedia of Psychology, 1-2. https://doi.org/10.1002/9780470479216.cor psy0467

Drews, R., Chiviacowsky, S., \& Wulf, G. (2013). Children's motor skill learning is influenced by their conceptions of ability. Journal of Motor Learning and Development, 1 , 38-44. https://doi.org/10.1123/jmld.1.2.38

Flôres, F. S., Schild, J. G., \& Chiviacowsky, S. (2015). Benefits of external focus instructions on the learning of a balance task in children of different ages. International Journal of Sport and Exercise Psychology, 46, 311-320. http://dx.doi.org/10.7352/IJSP.2015.46.311

Gonçalves, G. S., Cardozo, P. L., Valentini, N. C., \& Chiviacowsky, S. (2018). Enhancing performance expectancies through positive comparative feedback facilitates the learning of basketball free throw in children. Psychology of Sport and Exercise, 36 , 174-177. https://doi.org/10.1016/j.psychsport.2018. 03.001

Gonzalez, D. H., \& Chiviacowsky, S. (2018). Relatedness support enhances motor learning. Psychological Research, 82, 439447. http://dx.doi.org/10.1007/s00426-0160833-7

González-Cutre, D., Romero-Elías, M., JiménezLoaisa, A., Beltrán-Carrillo, V. J., \& 
Hagger, M. S. (2020). Testing the need for novelty as a candidate need in basic psychological needs theory. Motivation and Emotion, 44, 295-314. https://doi.org/10.1007/s11031-019- 098127

González-Cutre, D., Sicilia, A., Sierra, A. C., Ferriz, R., \& Hagger, M. S. (2016). Understanding the need for novelty from the perspective of self-determination theory. Personality and Individual Differences, 102, 159-169. doi:10.1016/j.paid.2016.06.036

Harter, N. M., Cardozo, P. L., \& Chiviacowsky, S. (2019). Conceptions of ability influence the learning of a dance pirouette in children. Journal of Dance Medicine $\mathcal{E}$ Science, 23, 167-172. http://dx.doi.org/10.12678/1089313X.23.4.167

Henderlong, J., \& Lepper, M. R. (2002). The effects of praise on children's intrinsic motivation: A review and synthesis. Psychological Bulletin, 128, 774-795. http://dx.doi.org/10.1037/00332909.128.5.774

Iwatsuki, T., Shih, H. T., Abdollahipour, R., \& Wulf, G. (2019). More bang for the buck: autonomy support increases muscular efficiency. Psychological Research, 1-7. http://dx.doi.org/0.1007/s00426-01901243-w

Jaitner, D., \& Mess, F. (2019). Participation can make a difference to be competitive in sports: A systematic review on the relation between complex motor development and self-controlled learning settings. International Journal of Sports Science \& Coaching, 14, 255-269. https://doi.org/10.1177/1747954118825063

Kamins, M. L., \& Dweck, C. S. (1999). Person versus process praise and criticism: Implications for contingent self-worth and coping. Developmental Psychology, 35, 835-847. https://doi.org/10.1037/00121649.35.3.835

Katz, I., Assor, A., Kanat-Maymon, Y., \& BerebyMeyer, Y. (2006). Interest as a motivational resource: Feedback and gender matter, but interest makes the difference. Social Psychology of Education, 9, 27-42. http://dx.doi.org/10.1007/s11218005-2863-7

Lemos, A., Wulf, G., Lewthwaite, R., \& Chiviacowsky, S. (2017). Autonomy support enhances performance expectancies, positive affect, and motor learning. Psychology of Sport and Exercise,
31 , 28-34. https://doi.org/10.1016/j.psychsport.2017. 03.009

Lessa, H. T., Tani, G., \& Chiviacowsky, S. (2018). Benefits of enhanced expectancies through temporal-comparative feedback for motor learning in older adults. International Journal of Sport Psychology, 49, 521-530.

http://dx.doi.org/10.7352/IJSP.2018.49.521

Lewthwaite, R., \& Wulf, G. (2012). “Motor learning through a motivational lens. In N. J. Hodges \& A. M. Williams (Eds.). Skill Acquisition in Sport: Research, Theory $\mathcal{E}$ Practice. (London: Routledge), 173-191. https://doi.org/10.4324/9780203133712

McAuley, E., Duncan, T., \& Tammen, V. V. (1989). Psychometric properties of the Intrinsic Motivation Inventory in a competitive sport setting: A confirmatory factor analysis. Research Quarterly for Exercise and Sport, 60, 48-58. https://doi.org/10.1080/02701367.1989.106 07413

McAuley, E., Wraith, S., \& Duncan, T. E. (1991). Self-Efficacy, Perceptions of Success, and Intrinsic Motivation for Exercise. Journal of Applied Social Psychology, 21, 139-155. https://doi.org/10.1111/j.15591816.1991.tb00493.x

Palmer, K., Chiviacowsky, S., \& Wulf, G. (2016). Enhanced expectancies facilitate golf putting. Psychology of Sport and Exercise, 22, 229-232. https://doi.org/10.1016/j.psychsport.2015. 08.009

Ryan, R. M., \& Deci, E. L. (2000). Selfdetermination theory and the facilitation of intrinsic motivation, social development, and well-being. American Psychologist, $\quad 55, \quad 68-78$. http://dx.doi.org/10.1037//0003066x.55.1.68.

Ryan, R. M., \& Deci, E. L. (2020) Intrinsic and extrinsic motivation from a selfdetermination theory perspective: Definitions, theory, practices and future directions. Contemporary Educational Psychology, 101860. https://doi.org/10.1016/j.cedpsych.2020.1 01860

Saemi, E., Wulf, G., Varzaneh, A. G., \& Zarghami, M. (2011). Feedback after good versus poor trials enhances motor learning in children. Brazilian Journal of Physical Education and Sport, 25, 673-681. 
Sanli, E. A., Patterson, J. T., Bray, S. R., \& Lee, T. D. (2013). Understanding self-controlled motor learning protocols through the selfdetermination theory. Frontiers in Psychology, 3, 611. https://doi.org/10.3389/fpsyg.2012.00611

Schmidt, R. A., Lee, T. D., Winstein, C. J., Wulf, G., \& Zelaznik, H. N. (2019). Motor control and learning: A behavioral emphasis (6th edition). Champaign, IL: Human Kinetics. Ste-Marie, D. M., Vertes, K. A., Law, B., \& Rymal, A. M. (2013). Learner-controlled selfobservation is advantageous for motor skill acquisition. Frontiers in Psychology, 3, 556. https://doi.org/10.3389/fpsyg.2012.00556

Trempe, M., Sabourin, M., \& Proteau, L. (2012). Success modulates consolidation of a visuomotor adaptation task. Journal of Experimental Psychology: Learning, Memory, and Cognition, 38, 52-60. https://doi.org/10.1037/a0024883

Vansteenkiste, M., Ryan, R. M., \& Soenens, B. (2020). Basic psychological need theory: Advancements, critical themes, and future directions. Motivation and Emotion,
44, 1-31. https://doi.org/10.1007/s11031019-09818-1

Whitehead, J. R., \& Corbin, C. B. (1991). Effects of Fitness Test Type, Teacher, and Gender on Exercise Intrinsic Motivation and Physical Self Worth. Journal of School Health, 61, 1116. https://doi.org/10.1111/j.17461561.1991.tb07850.x

Wise, R. A. (2004). Dopamine, learning and motivation. Nature Reviews Neuroscience, 5, 483-494. http://dx.doi.org/10.1038/nrn1406.

Wulf, G., \& Lewthwaite, R. (2016). Optimizing performance through intrinsic motivation and attention for learning: The OPTIMAL theory of motor learning. Psychonomic Bulletin E Review, 23, 1382-1414. http://dx.doi.org/10.3758/s13423-0150999-9

Ziv, G., Lidor, R., \& Lavie, M. (2019). Enhanced expectancies in golf putting-a replication study with increased ecological validity. International Journal of Sport and Exercise Psychology, 1-12. https://doi.org/10.1080/1612197X.2019.163 7362 